\title{
Formar o espectador infanto-juvenil para ver e fazer teatro
}

\author{
Roger Deldime
}

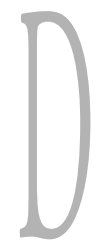
esde a sua criação, em 1970, o Centro de Sociologia do Teatro da Universidade Livre de Bruxelas orienta suas investigações para três direçôes complementares: a criação, a recepção e a mediação. A sociologia da criação teatral se preocupa em analisar a dialética existente entre as raízes culturais referentes ao contexto sócio-histórico da criação e as raízes vitais do artista criador. A sociologia da recepção teatral confere ao espectador um papel essencial no processo teatral, considerando o teatro não apenas como uma representação que se faz diante do público, mas, antes de tudo, como um conjunto organizado de interações, diferentes e modificáveis, que se estabelecem entre cada espectador e o espetáculo. A sociologia da mediação teatral cuida da investigação do terceiro espaço, aquele que se situa entre a criação e a recepção, atuando nessa "distância" que existe entre os avanços de toda criação digna de levar este nome e os espectadores, que, para perceberem e apreciarem esta criação, empreendem uma atitude que é proveniente mais de uma aquisição cultural do que de um dom natural, espontâneo ou inato.

\section{Da pesquisa à ação: \\ La Montagne Magique}

Habituar crianças e jovens a se relacionarem com o teatro enquanto espectadores atentos, estimulá-los a experimentar a arte dramática enquanto aprendizes criativos, além de iniciar os seus professores nos domínios desta arte, convidando-os a se tornarem parceiros interessados, assim se pode definir a especificidade do projeto cultural e educativo do Teatro La Montagne Magique, criado em 1995. Esta instituição teatral oferece espetáculos criados por companhias profissionais, que abordam temáticas diversas e se apóiam em estéticas contrastantes. A apresentação das peças é acompanhada de atividades que visam ampliar a informação dos professores e das famílias acerca dos espetáculos, sensibilizar os espectadores infanto-juvenis e oferecer prolongamentos artísticos nas salas de aula.

La Montagne Magique propõe ainda cursos com o objetivo de aprimorar a formação teatral de professores e futuros professores, além de estimular a expressão artística de crianças e jovens, através da realização de montagens que

Roger Deldime é diretor do Centro de Sociologia do Teatro da Universidade Livre de Bruxelas (Bélgica) e do Teatro La Montagne Magique. 
são apresentadas, nos finais de período, durante festivos e encontros de teatro escolar.

A experiência demonstra: a formação do espectador infanto-juvenil precisa estar calcada, ao mesmo tempo, no "ver", no "fazer", no "mostrar" e na formação teatral dos professores. ${ }^{1}$

\section{A quadriga ver-formar- praticar-representar}

Integradora e multidisciplinar, a formação do espectador reúne em um mesmo projeto: a criação artística profissional, a montagem teatral realizada pelos alunos, a iniciação dos professores, a recepção das obras pelos espectadores infanto-juvenis, e a expressão dos indivíduos e grupos através do jogo dramático.

\section{Etapas $^{2}$}

1) Descoberta do espetáculo, seguida de um encontro dos alunos com os artistas, que explicitam as intenções dramatúrgicas e a decodificação dos signos cênicos, chamando a atenção dos jovens para algumas das características relevantes do espetáculo. Focalizar o olhar dos espectadores para o papel da iluminação ou da música, a utilização do espaço, a função de um figurino ou de um adereço, a atitude de um personagem...

2) Formação teatral dos professores, ministrada pelos artistas do espetáculo, durante um ou mais finais de semana.

3) Os alunos das escolas participantes criam as próprias cenas teatrais. A equipe do Teatro La Montagne Magique fornece assessoria aos professores, ajudando-os a suplantar os obstáculos imprevistos durante o processo de criação.

4) As turmas mostram suas cenas no Teatro La Montagne Magique, quando se promo- ve o "Encontro de Teatro Escolar", em que os alunos apresentam-se no palco de um verdadeiro teatro, que dispóe de logística e aparatos técnicos profissionais, o que valoriza as criações dos alunos e legitima o trabalho dos professores envolvidos.

\section{Um exemplo: \\ ver e representar Shakespeare}

Quando falamos sobre explorar o teatro no ensino secundário, pensamos imediatamente no estudo de um texto. Porém, um texto só existe quando se traduz em ação sobre o palco, pois um texto teatral é escrito para ser representado. Com a implementação do projeto "Ver e Fazer Shakespeare", o texto toma corpo, o que possibilita que os professores percebam a sua singularidade em relação aos demais textos literários.

\section{Formar}

Durante três dias são propostas e realizadas oficinas de formação com os professores das escolas, sob a coordenação de Jean-Claude Berutti e Christian Baggen, encenadores especialistas em Shakespeare. Depois de uma rápida apresentação do dramaturgo inglês, com exposições acerca do seu tempo e da concepção que se tinha de teatro em sua época, os coordenadores propõem uma aproximação inteligente de um texto escolhido pelos participantes, imediatamente seguida de jogos corporais e vocais visando a apreensão da obra. Em seqüência, exercícios de criação de personagens estimulam a expressão dos participantes, ao mesmo tempo em que possibilitam a exploração de diferentes técnicas teatrais. As encenaçôes de alguns trechos da obra de Shakespeare encerram esta oficina de formação, completada por um curso dirigido por Paul Harman, no mesmo momento

1 Nota do tradutor: é importante observar que, na Bélgica, não existem professores de teatro atuando nas escolas e a arte teatral é trabalhada por professores responsáveis por outras disciplinas curriculares.

2 A coordenação é de Jeanne Pigeon, responsável pelos projetos de formação. 
em que este encenador inglês está com uma peça em cartaz no Teatro La Montagne Magique.

\section{Ver}

O espetáculo proposto aos adolescentes vem da Inglaterra, trata-se de Romeu e Julieta, criado pela Cleveland Theatre Company. Reduzida ao essencial, mas sem perder o texto original, a peça é interpretada por três atores profissionais, que representam vários personagens. Os espectadores são instalados ao redor do palco, como na época elisabetana, e a encenação busca instaurar um espírito de jogo: as mudanças do cenário, que tem um tom minimalista e polivalente, são feitas à vista do espectador, assim como a troca de figurinos e de personagens. A montagem estimula o gosto pela poesia do texto e possibilita a descoberta de que podemos traduzir, adaptar e representar Shakespeare de muitas maneiras, trabalhando com esse monumento da cultura, considerado o grande clássico dos clássicos, sem perder a liberdade criativa.

\section{Jogar}

Motivados por esta representação, e estimulados por seus professores, que realizaram uma oficina prévia de formação, os alunos, por sua vez, mergulham num processo de investigação e montagem dos textos que escolheram para trabalhar. A evolução das oficinas de montagem é coordenada pelo ator Christian Baggen; além disto, os professores participam de reuniōes freqüentes com Jean Lucke, responsável pelos projetos desenvolvidos na Montagne Magique.

\section{Representar}

Cada oficina apresenta, por fim, a sua realização no palco do Teatro, em um evento que se dá durante todo o dia e reúne todos os participantes. As técnicas utilizadas nas montagens dos alunos - seja na adaptação da obra, no modo de falar o texto (que, mesmo revelando a inexperiência dos atores, mantém uma forte vitalidade), nos cantos, nas danças, nos coros falados, ou no próprio texto de Shakespeare (em francês ou inglês) - fazem surgir um autor ex- tremamente moderno. Através de fragmentos de Macbeth, Romeu e Julieta, Como Gostais, Otelo, Ricardo III, Júlio César, Hamlet, O Mercador de Veneza e A Megera Domada, os adolescentes apropriam-se livremente do gênio de Shakespeare, carregando de dinamismo e espontaneidade textos que em recitais magistrais, por vezes, se tornam profundamente entediantes. Encenações despojadas e interpretações audaciosas, fornecendo diferentes visões de um mesmo autor, para não dizer de um mesmo fragmento de texto. E tudo isto sem um instante sequer de tédio! Os jovens, originários de diversos meios culturais, lançaram um olhar próprio sobre a nossa época. Que bela lição de universalidade!

\section{Formação do espectador: resultado de um paciente trabalho de educação}

A implementação de projetos como esses afasta as práticas de formação de espectadores do empobrecimento pedagógico e do confinamento institucional; práticas que, após longo tempo de experimentos, ocupam atualmente um lugar legítimo no campo educacional. A arte e a educação, desta maneira, se completam, estabelecendo uma relação de respeito mútuo, na qual uma depende da outra para equilibrar permanentemente a compreensão acerca do sentido da formação de crianças e jovens.

A gestão destes projetos, porém, exige enorme gasto de energia, além de um importante trabalho de coordenação e uma observação atenta sobre cada uma das diversas etapas da realização, e é aqui que se localiza o indispensável trabalho de mediação desempenhado por La Montagne Magique. Este é um preço necessário a ser pago, se quisermos evitar a esclerose causada pela institucionalização.

O oferecimento de diversas criações artísticas profissionais ao público infanto-juvenil, a iniciação dessas crianças e jovens enquanto espectadores, a formação teatral dos professores, o estímulo às práticas de expressão dramática, a montagem de cenas pelos alunos, são atividades 
que exigem um esforço contínuo, esforço este que sustenta toda prática em educação. Para ser eficaz e convincente, a formação do espectador teatral precisa estar vinculada às idéias de duração e de permanência, encarando o tempo como um eminente desafio da ação educacional.

\section{Algumas obras do autor sobre a formação de espectadores}

DELDIME, Roger. Prolongements artistiques et pédagogiques d'un spetacle de marionettes. Bruxelles: UEEB, 1972. . Influence de l'action pédagogique sur la réception d'un spetacle. Namur: Cacef, 1973. . Les jeunes face au spetacle idéologique. Bruxelles: Jeb, 1975. . Le théâtre pour enfants. Bruxelles: De Boeck, 1976. . La mémoire du jeune spectateur. Bruxelles: De Boeck/Editions Universitaires, 1988. . Le quatrième mur. Carnières (Morlanwelz): Lansman, 1990. . Fou de théatre. Carnières (Morlanwelz): Lansman, 1993.

. Lês trois cercles de l'initiation théâtrale des jeunes. Carnières (Morlanwelz): Lansman, 2002. 